\title{
Caracterização de Filmes Finos a Base de Estanho Dopados com Nióbio para Células
}

\section{Solares ${ }^{1}$}

Bianca Vanjura Dias ${ }^{2}$, Aline Viomar ${ }^{3}$, Guilherme Arielo Rodrigues Maia ${ }^{3}$, Paloma Detlinger ${ }^{4}$, Fernando Reinoldo Scremin ${ }^{5}$, Augusto Celso Antunes ${ }^{6}$, Paulo Rogério Pinto Rodrigues ${ }^{6}$

1 Aceito para publicação no $3^{\circ}$ Trimestre de 2014

2 Mestranda em Química na Universidade Estadual do Centro- Oeste, biavanjura@yahoo.com.br

${ }^{3}$ Doutorandos em Química na Universidade Estadual do Centro- Oeste, alineviomar@gmail.com; Guilherme.arielo@gmail.com

${ }^{4}$ Acadêmica em Química na Universidade Estadual do Centro- Oeste, palomadetlinger@ hotmail.com

${ }^{5}$ Pós- Doutorando em Química na Universidade Estadual do Centro- Oeste, screminfr@gmail.com

${ }^{6}$ Professores do Departamento de Química na Universidade Estadual de Ponta Grossa, ac_antunes@uol.com.br; prprodrigues@gmail.com.

Resumo: As células fotovoltaicas constituídas de filmes finos de óxidos metálicos são promissoras para a conversão de energia solar em energia elétrica devido ao custo reduzido e as vantagens ambientais. O objetivo deste trabalho é a produção de filmes finos a base de estanho pelo método Pechini visando à aplicação em células solares. Os filmes obtidos foram caracterizados por Microscopia Eletrônica de Varredura (MEV), Espectroscopia de Energia Dispersiva (EDS), Difração de Raios X (DRX) e Espectroscopia de Impedância Eletroquímica (EIE). Os resultados de MEV e EDS indicaram que resinas com viscosidade alta geram filmes pouco homogêneos. Os diagramas de impedância indicaram que o filme sobre o substrato de ITO aumenta a resistência do sistema. 
Palavras-chave: sustentabilidade; energia fotovoltaica; sol-gel.

\section{Characterization Of Thin Films Tin-Based Doped Niobium For Solar Cells}

Abstract: Photovoltaic cells composed of thin films of metal oxide are promising for the conversion of solar energy. This is due to the reduced cost and environmental advantages. The objective of this paper is the thin films production by Pechini method aiming solar cells application. The films were characterized by Scanning Electron Microscopy (SEM), Energy Dispersive Spectroscopy (EDS), X-ray Diffraction (XRD) and Electrochemical Impedance Spectroscopy (EIS). The results of SEM and EDS indicated that resins with high viscosity generate non homogeneous films. The impedance diagrams indicate that the film on the ITO substrate increases resistance of the system.

Keywords: sustainability; photovoltaics; sol-gel. 


\section{Introdução}

A matriz energética mundial é baseada em fontes de energia não renováveis, segundo dados de 2010 do Ministério de Minas e Energia apenas 13\% da energia utilizada no mundo é renovável (Epe, 2013). Todavia, a escassez das reservas petrolíferas vem impulsionando o desenvolvimento de tecnologias voltadas para a produção de energia de fontes alternativas (Lior, 2008).

A energia solar destaca-se por possuir grande potencial para suprir a demanda energética mundial, estima-se que o planeta receba diariamente $1,2 \times 10^{17} \mathrm{~W}$ de energia vinda do sol. (Oliveira, 2008; Kelman et al., 2005; EPIA, 2006). O Brasil é um país bastante promissor no desenvolvimento de tecnologia solar, visto que está posicionado próximo a linha do Equador e recebe alta incidência de raios solares em grande parte do território nacional (Tiba et al., 2000).

O aproveitamento da energia solar para a produção de energia elétrica é o principal foco de estudo. O dispositivo capaz de fazer essa conversão é denominado célula fotovoltaica (Oliveira, 2008). Em especial, as células solares de segunda geração ganham destaque por apresentarem espessura inferior a $1 \mu \mathrm{m}$, assim geram menos resíduos decorrentes do processo de produção, minimizando o impacto ambiental, e reduzindo os custos, além da sua fácil incorporação nos projetos arquitetônicos (Conti, 2001; Scalvi et al., 2011).

O dióxido de estanho é um dos materiais semicondutores mais utilizados na produção de filmes finos. Segundo Jarsebski e Marton as características do $\mathrm{SnO}_{2}$ que o diferem dos demais óxidos semicondutores, são formar filmes transparentes, dopagem e possuir os elétrons do orbital d estáveis apesar de não apresentar estrutura cúbica (Bernardi et al., 2002; Montero et al., 2010). Apesar de apresentar a característica natural de condução, freqüentemente são adicionados elementos para melhorar as propriedades elétricas do $\mathrm{SnO}_{2}$, como flúor, antimônio, tântalo e nióbio (Rajpure et al., 2000). A dopagem de $\mathrm{SnO}_{2}$ com nióbio apresenta-se como uma alternativa promissora, além de que o Brasil possui uma das maiores reservas de nióbio do mundo.

A obtenção de filmes finos pelo método sol-gel é vantajosa, pois permite controlar melhor a espessura dos filmes e garante alta homogeneidade (Hiratsuka et al., 1995), características essenciais para aplicação em células solares. Outro fator determinante na produção de filmes finos é a viscosidade do sol, que quando não é finamente controlada 
ocasiona defeitos morfológicos tais como trincas e bolhas na superfície dos filmes, impedindo a passagem de corrente elétrica (Bernardi et al., 2002).

O presente trabalho tem como objetivo obter filmes finos de $\mathrm{SnO}_{2}$ dopados com nióbio em superfície vítrea condutora pelo método Pechini visando o emprego em células fotovoltaicas.

\section{Materiais e métodos}

O tartarato de estanho empregado foi obtido por síntese utilizando como reagentes de partida o $\mathrm{SnCl}_{2} \cdot 2 \mathrm{H}_{2} \mathrm{O}$ e ácido tartárico seguindo a metodologia proposta por Santos et al (2000).

Os filmes de estanho foram produzidos pelo método Pechini (Pechini, 1967). As proporções molares dos reagentes foram 4 mols de ácido cítrico, 16 mols de etileno glicol e 1 mol de tartarato de estanho. O processo de obtenção da resina inicia-se com a mistura do precursor de estanho em água destilada sobre agitação magnética e temperatura ambiente. Em seguida, foi adicionado o ácido cítrico e o etileno glicol, ambos sob agitação magnética constante e temperatura de $60{ }^{\circ} \mathrm{C}$. Para completa dissolução dos precursores foram adicionadas algumas gotas de $\mathrm{HNO}_{3}$ concentrado e a solução permaneceu sob agitação por mais 1 hora.

O reagente utilizado para a dopagem da resina polimérica foi $o$ $\left[\mathrm{NH}_{4} \mathrm{H}_{2}(\mathrm{NbO})\left(\mathrm{C}_{2} \mathrm{O}_{4}\right)_{3} \mathrm{nH}_{2} \mathrm{O}\right]$ de pureza analítica. A dopagem foi realizada pela adição de $5 \%$ em mol do composto na resina polimérica sob agitação constante até completa dissolução.

A deposição do filme no substrato vítreo foi realizada por dip coating com velocidade de imersão/emersão controlada. Após cada camada de resina depositada a amostra foi seca em estufa a $100{ }^{\circ} \mathrm{C}$ por 20 minutos, até obter 4 camadas e a amostra foi queimada em seguida. A queima foi realizada em mufla a $470{ }^{\circ} \mathrm{C}$ por 4 horas com taxa de aquecimento de $1{ }^{\circ} \mathrm{C} \mathrm{min}^{-1}$.

Para os testes eletroquímicos o mesmo procedimento descrito acima foi realizado tendo como substrato uma placa vítrea condutora ITO. Antes dos testes eletroquímicos as amostras foram imersas em uma solução alcoólica de SAM (Self-Assembly Monolayers) a 90 ppm, seguindo o procedimento proposto por Fáveri (2008)

A caracterização da morfologia superficial das amostras foi avaliada por microscopia eletrônica de varredura (MEV), em microscópio Tescan® Vega 3. A composição superficial foi determinada por espectroscopia de energia dispersiva (EDS). 
A estrutura foi avaliada por difração de raios-X (DRX) em um equipamento D2 Phaser, Bruker, com radiação $\mathrm{CuK} \alpha=1,54$, e detector LynxEye, Bruker, a varredura foi de 10 a 80 graus.

Para a caracterização eletroquímica foi empregada a técnica espectroscopia de impedância eletroquímica, utilizando um potenciostato Gamry PC4-300/EIS300. A célula eletroquímica era composta de dois eletrodos, sendo o substrato vítreo condutor recoberto com o filme estudado como eletrodo de trabalho e platina como contra eletrodo e eletrodo de referência, utilizados em curto. A composição do eletrólito utilizado é $0,5 \mathrm{molL}^{-1}$ de terc-butil piridina, 0,6 molL $\mathrm{m}^{-1}$ de iodeto de tetrabutilamônio, 0,1 de iodeto de lítio e $0,1 \mathrm{molL}^{-1}$. O ensaio foi realizado na ausência e presença de luz proveniente de uma lâmpada comercial com potência de 100 Watts.

\section{Resultados e discussão}

Os filmes obtidos a partir da diluição da resina tiveram sua morfologia superficial analisada por microscopia eletrônica de varredura e estão apresentados na Figura 1.
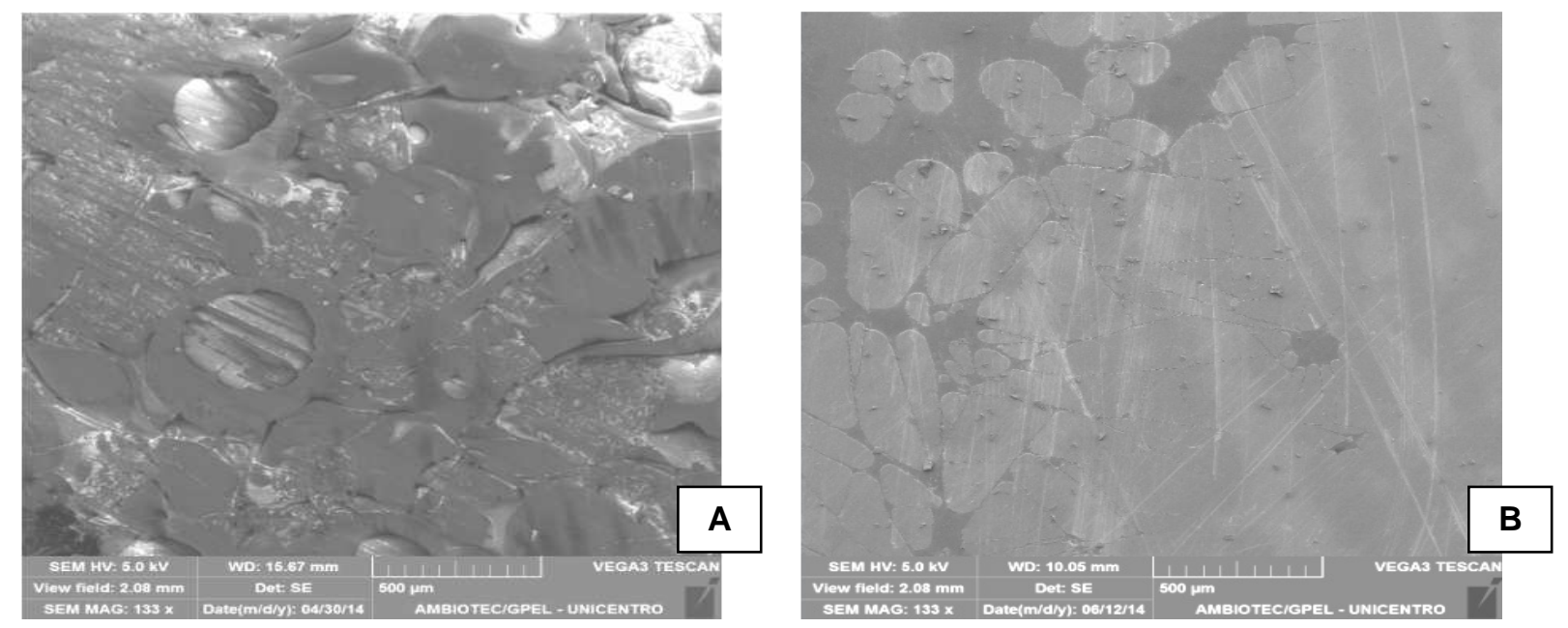

Figura 1. Imagens geradas por MEV de amostras recobertas por filmes a base de estanho (A) sem diluição e (B) diluída a $25 \%$.

Observa-se na Figura 1 A que a amostra obtida com resina sem diluição apresenta uma superfície pouco homogênea com muitos defeitos decorrentes do acúmulo de resina e da formação de bolhas. A superfície da amostra obtida com a resina diluída, mostrada na Figura $1 \mathrm{~B}$, é mais uniforme quando comparada a amostra obtida com resina sem diluição, Figura 1 
A.

A composição superficial das amostras foi avaliada por EDS e os resultados são mostrados na Tabela 1.

Tabela 1. Composição superficial das amostras contendo filme a base de estanho obtidos por EDS.

\begin{tabular}{rlll}
\hline \multirow{2}{*}{ Amostra } & \multicolumn{2}{l}{ Elementos \% em massa } \\
\cline { 2 - 4 } & Sn & Si & O \\
\hline Sem diluição & 12,64 & 27,69 & 59,10 \\
Diluída a $25 \%$ & 50,18 & 9,78 & 31,57 \\
\hline
\end{tabular}

Na tabela 1 observa-se que a amostra diluída a $25 \%$ contem uma porcentagem de estanho mais elevada quando comparada a amostra sem diluição. A menor viscosidade permite a melhor aderência e distribuição do filme na superfície. As imagens da superfície da amostra com filme antes e após o teste de aderência é apresentada na Figura 2.
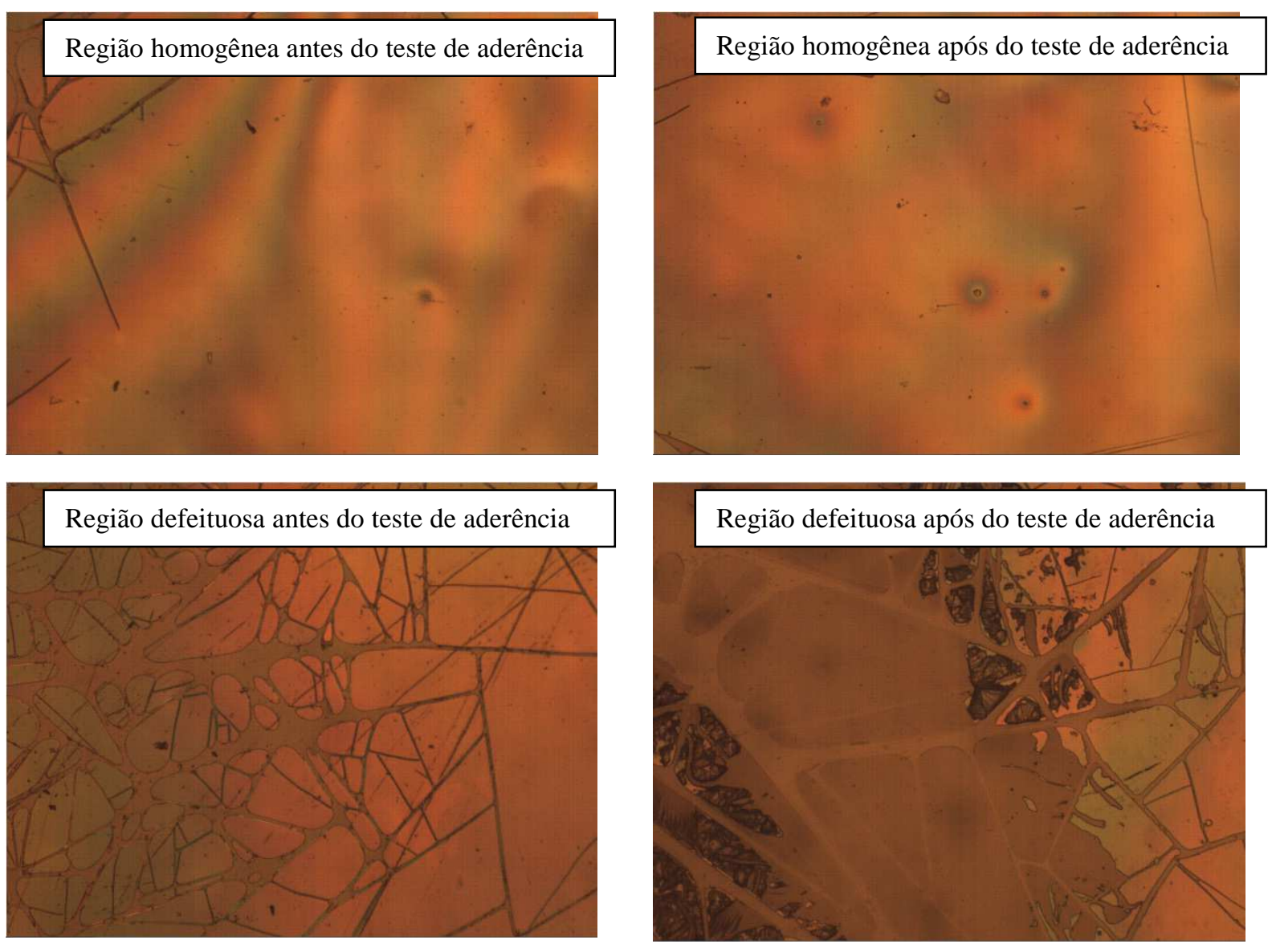

Revista Brasileira de Energias Renováveis, v. 3, p. 212- 222, 2014 
Figura 2. Micrografias da superfície do substrato vítreo contendo filme a base de estanho antes e após o teste de aderência em regiões sem e com defeitos.

As imagens apresentadas na Figura 2 mostram que em regiões homogêneas não houve desplacamento do filme após o teste realizado, indicando que o filme é aderente ao substrato vítreo. Todavia, em regiões defeituosas o filme apresentou baixa aderência, foi quase que completamente retirado da superfície.

O resultado da análise de raios $\mathrm{X}$ do filme obtido é apresentado na Figura 3.

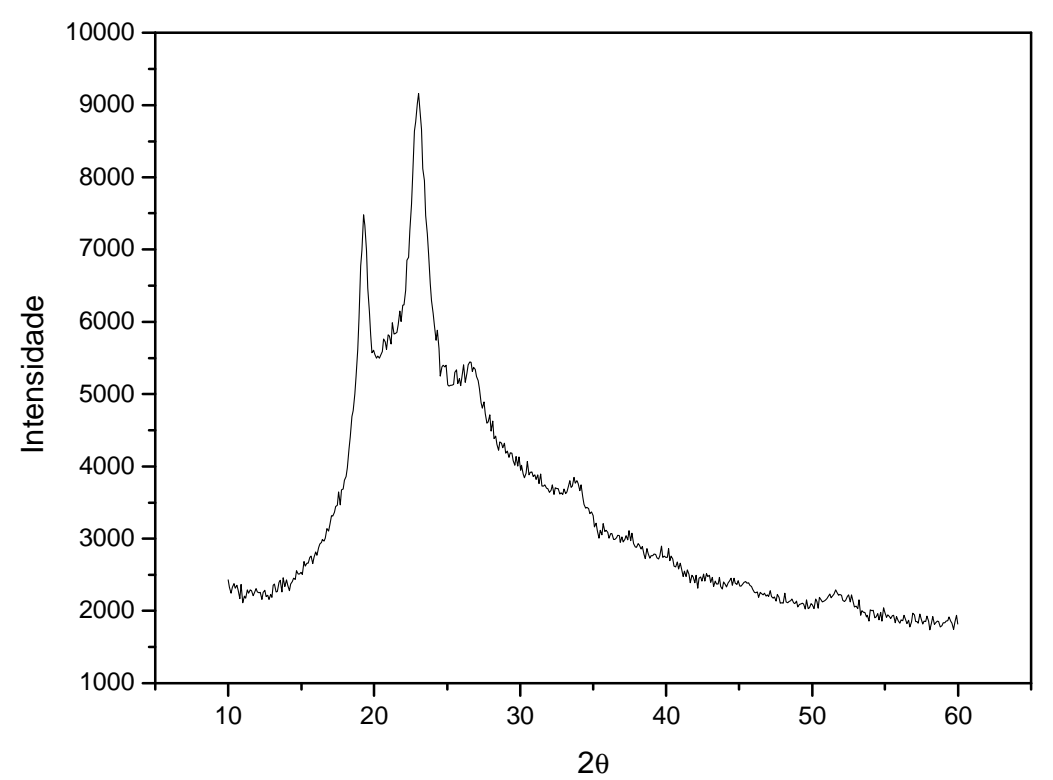

Figura 3. Difratograma da superfície do substrato vítreo contendo filme a base de estanho com diluição de $25 \%$.

O difratograma mostrado na Figura 3 apresenta características amorfas, devido ao substrato vitreo utilizado. A análise para identificação da amostra foi realizada utilizando o software JCPDS, todavia constatou-se uma possível mistura de materiais, sendo o oxalato de estanho o componente majoritário. Dal Santos et al. (2012) produziu filmes semelhantes e obteve $\mathrm{SnO}_{2}$ na fase rutilo.

A espectroscopia de impedância eletroquímica foi utilizada para análise da resistência do sistema na presença e ausência de luz. O diagrama é mostrado na Figura 4. 


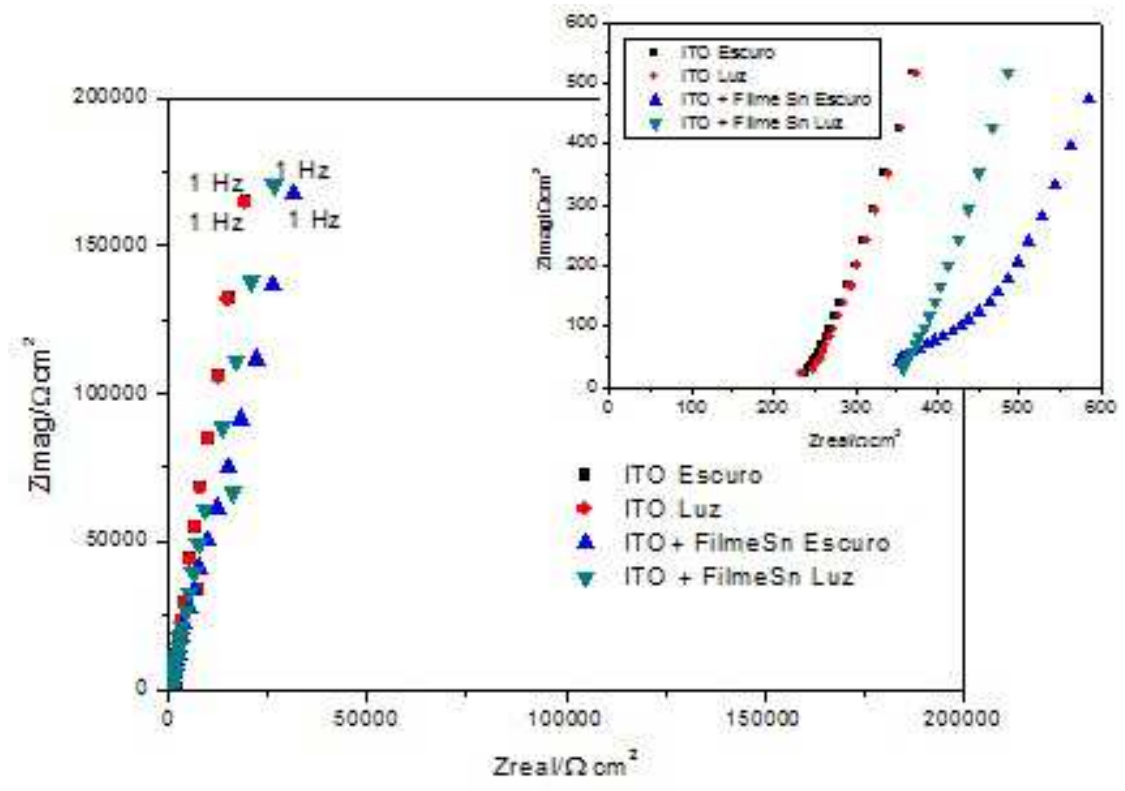

Figura 4. Diagrama de impedância eletroquímica tipo Nyquist obtido para a amostra de ITO e ITO+Filme de estanho dopado com 5\% de nióbio contendo SAM testado em meio de solução de iodo na presença e ausência de luz.

Os resultados apresentados na Figura 4 indicam que as amostras testadas apresentam comportamento capacitivo que está relacionado ao carregamento da dupla camada elétrica. Não existe diferença significativa entre as curvas obtidas para o ITO e ITO+Filme Sn, também não é observada nenhuma diferença para a amostra ITO+Filme na presença e ausência de luz indicando que o sistema não apresenta fotossensibilidade.

A resistência do sistema foi avaliada pelo primeiro ponto obtido no diagrama de impedância, os resultados são apresentados na Tabela 2.

Tabela 2. Resistência do sistema obtidos por EIE em solução iodo

\begin{tabular}{ll}
\hline Amostra & Resistência Eletrodo/Solução $\left(\mathbf{\Omega} \mathbf{c m}^{\mathbf{2}}\right)$ \\
\hline ITO Escuro & 236,7 \\
ITO Luz & 238,8 \\
ITO+Filme Sn Escuro & 350,7 \\
ITO+Filme Sn Luz & 357,6 \\
\hline
\end{tabular}

Os valores de resistência, apresentados na tabela 2 , mostram que a presença de luz a 
100 Watts não produz efeito considerável sobre o filme para emprego como célula fotovoltaica e que o filme de estanho aumenta a resistência do sistema, também pode ser observado na ampliação da Figura 4.

\section{Conclusões}

Os filmes gerados pelo método proposto apresentam defeitos morfológicos. Os defeitos são mais acentuados em amostras obtidas com resina polimérica de elevada viscosidade. Por DRX constatou-se que a amostra não é composta apenas por $\mathrm{SnO}_{2}$.

Os resultados obtidos por espectroscopia de impedância eletroquímica indicam que os filmes produzidos não apresentam fotossensibilidade e aumentam a resistência eletrodo/solução.

\section{Agradecimentos}

Fundação Araucária, CAPES, CNPQ e Finep

\section{Referências}

BERNARDI, M.I.B. et al. Influence of the concentration of $\mathrm{Sb}_{2} \mathrm{O}_{3}$ and the viscosityof the precursor solution on the electrical and optical properties of $\mathrm{SnO}_{2}$ thin films produced by the Pechini Method. Thin Solid Films. v.405, p.228-233, 2002.

CONTI, T.G. Obtenção e caracterização elétrica de filmes finos de $\mathrm{SnO}_{2}: \mathrm{Sb}$.2011. 94p. Dissertação (Mestrado em Ciência e Engenharia de Materiais) Universidade Federal de São Carlos- UFSCAR, São Carlos.

DAL SANTOS, M.A. et al. Filmes finos nanoestruturados obtidos pelo método dos precursores poliméricos. Semina: Ciências Exatas e Tecnológicas, Londrina, v.33, n.2, p. 243-254, 2012

EL CHAAR, L.; LAMONT, L.A. e EL ZEIN, N. Review of photovoltaic technology. Renewable and Sustainable Energy Reviews, v. 15, p.2165-2175, 2011.

EPIA. Solar Generation: Solar Electricity for over one billion people and two billion jobs by 2020, 2006. Disponível em: 〈http://www.epia.org/home/> 
EMPRESA DE PESQUISA ENERGÉTICA (EPE). Balanço energético nacional 2013: Ano base 2012. Rio de Janeiro, 288p, 2013.

FAVERI, C. de. Aplicação de moléculas auto-organizáveis (SAM) em filmes finos de $\mathrm{SnO}_{2}$. 2008. 144p. Dissertação (Mestrado em Química Aplicada) Universidade Estadual de Ponta Grossa - UEPG, Ponta Grossa.

HIRATSUKA, R. S.; SANTILLI, C. V.; PULCINELI, S. H. O processo sol-gel: uma visão físico-química. Química Nova, São Paulo, v. 18, n.2, 1995.

KELMAN, J et al.. Atlas de Energia Elétrica do Brasil/Agência Nacional de Energia Elétrica. $2^{\mathrm{a}}$ Edição, Brasília: ANEEL, 2005. 243p. Disponível em: http://www.aneel.gov.br/aplicacoes/ATLAS/download.htm

LIOR, N. Energy resources and use: The present situation and possible paths to the future. Energy, v.33, p.842-857, 2008.

MONTERO, J; HERRERO, J. e GUILLEN, C. Preparation of reactively sputtered Sb-doped $\mathrm{SnO}_{2}$ thin films: structural, electrical and optical properties. Solar Energy Materials and Solar Cells. v.94, p.612-616, 2010.

OLIVEIRA, H.E.Tecnologia fotovoltaica em filmes finos (películas delgadas). 2008. 56p. Monografia (Pós-Graduação em Formas alternativas de Energia), Universidade Federal de Lavras- UFL, Lavras.

PECHINI, M. P. US Patent 3330697, 11 de julho de 1967

RAJPURE, K.Y. et al. Effects of Sb dopping on properties of conductive spray deposited $\mathrm{SnO}_{2}$ thin films. Materials Chemistry and Phisycs. V.64, p.184-188, 2000.

SCALVI, L.V.A. et al Resistividade do filme depositado via sol-gel e estado de oxidação do dopante Ce na matriz SnO.2. Cerâmica. V.57, p.225-230, 2011.

TIBA, C. et al. Atlas Solarimétrico do Brasil: banco de dados solarimétricos. Recife: Ed. Universitária de UFPE, 2000. 111p. Disponível em: < http://www.cresesb.cepel.br/publicacoes/download/Atlas_Solarimetrico_do_Brasil_2000.pdf> 
VICHI, F.M. e MANSOR, M.T.C. Energia, meio ambiente e economia: O Brasil no contexto mundial. Química Nova, v.32, n.3, p.757-767, 2009. 